Int. J. Dev. Biol. 53: 1113-1117 (2009)

doi: $10.1387 / \mathrm{ijdb} .072526 \mathrm{mp}$

\title{
Heterologous expression of DsRed2 in young sponges (Porifera)
}

\author{
MARTIN PFANNKUCHEN* and FRANZ BRÜMMER \\ Universität Stuttgart, Biologisches Institut, Abteilung Zoologie, Stuttgart, Germany
}

\begin{abstract}
Sponges (Porifera) are currently considered to be the first branch off the Urmetazoa, common ancestors of all multicellular animals or metazoa. Research in the field of the developmental biology of sponges was restricted to morphological observations. Nowadays, research is mainly concentrated on larval development, primarily dealing with tissue formation. Already since 1907, methods for developing functional sponges from stem cells have been at hand. Functional freshwater sponges can be grown from stem cell populations originating from gemmulae. A number of poriferan sequences with high similarity to regulative genes in higher metazoa have already been found. We have now succeeded in heterologously expressing the red fluorescent protein DsRedN1 under the control of the cytomegalovirus promoter in young specimens of the freshwater sponge Spongilla lacustris. The protein folded correctly, polymerized and subsequently was detected by fluorescence microscopy. Reporting this expression system, we now consider this appealing system for early meatazoan development to be ready for molecular developmental biology and functional genetics research.
\end{abstract}

KEY WORDS: porifera, freshwater sponge, heterologous expression, functional sponge, DsRed2, CMV

\section{Introduction}

Even though the deep, molecular phylogeny of metazoa is discussed as being not fully resolved, sponges (phylum Porifera) are currently accepted to be the phylogenetically oldest, extant metazoa (Müller, 2003, Erpenbeck and Wörheide, 2007). They evolved during the Neoproterozoic, Neoproterozoic-Cambrian period (Xiao et al., 2005) and are grouped into three classes: the Hexactinellida, the Demospongiae and the Calcarea. Despite their phylogenetic position, branching off directly from the Urmetazoa at the base of all multicellular organisms, their morphology and body plan is already elaborated, even though referred to as modular.

Already in 1907, Wilson investigated the sponges' fascinating ability to regenerate their complex morphology from dissociated cells (Wilson, 1907). Their results already predicted the enormous plasticity of poriferan cell types and showed the sponge cells' ability to recreate a complex body structure from a solution of dissociated cells, which is nowadays exploited for modern biotechnological applications (Nickel et al., 2001). In this process the sponge cells undergo de-differentiation and re-differentiation processes. This is also the case for the two asexual forms of proliferation sponges are capable of, besides sexual proliferation: the simpler way is sheer fragmentation, and the more complex one is the building of gemmulae. The mainly rounded gemmula consists of a durable shell of spongin, which is often times enforced with siliceous gemmuloscleres. It is filled with nursing cells and archaeocytes, which are omnipotent stem cells of the sponge (Weissenfels, 1989). The gemmulae are built to overcome adverse conditions like starvation, freezing, drying as well as anoxia and to facilitate dispersal (Reiswig and Miller, 1998). The dormant or quiescent gemmulae hatch under favourable conditions (Ostrom and Simpson, 1978). During hatching the archaeocytes differentiate and find their place in the newly built morphology of the functional young sponge. Even though sponges show this enormous range of interesting cellular as well as organismic capabilities the porifera are still considered as the very basal metazoan life form (Müller et al., 2004b). Hence they are the organisms of choice to investigate the origin and base of morphogenesis, stem cells, and multicellularity in metazoa (Coutinho et

Abbreviations used in this paper: CMV, cytomegalovirus; DsRed, red fluorescent protein derived from Discosoma sp.

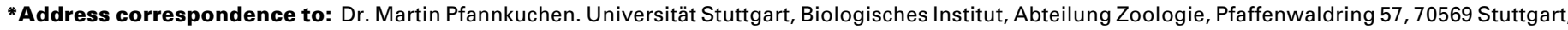
Germany. Fax: +49-711-6856-5096. e-mail: martin.pfannkuchen@bio.uni-stuttgart.de
} 
al., 2003; Müller et al., 2003; Müller et al., 2004c; Perovic-Ottstadt et al., 2004; Martindale, 2005; Steele, 2005). Promising results could already be achieved in identifying genes with high similarities to genes from higher metazoa, which are involved in the regulation of morphogenesis and stem cell regulation or even the regulation of apoptosis (Wiens and Müller, 2006).

Poriferan sequence homologues for the following genes are already identified: the transcription factors Brachyury and Tbx23-4-5from the T-box family, which are involved in the formation of mesodermal and endodermal structures, as well as presumably in the formation of the first body axis (Adell et al., 2003a, Müller et al., 2004b). Five sequences homologous to Fox Genes from the winged-helix/forkhead family, also involved in higher metazoan organogenesis (Adell and Müller, 2004). The homeodomaine genes Pax-2/5/8, from the paired class, and further three genes from the antennapedia and the lim/homeobox class which are up regulated during poriferan canal formation (Hoshiyama et al., 1998, Wiens et al., 2003). A sequence homologue to Iroquois genes was also demonstrated to be highly expressed during canal formation (Perovic et al., 2003). The membrane receptor Frizzled is part of the Wnt signal cascade and responsible for tissue polarity. Sequence homologues to Frizzled are shown to be up regulated in poriferan cell re-aggregation (Adell et al., 2003b).

In addition to the growing knowledge on genes presumably involved in morphogenesis, apoptosis and stem cell systems, another prerequisite for functional genetics is already given: for species from the suborder Spongillina Manconi \& Pronzato, 2002 comfortable culturing, hatching and regulation procedures are at hand. The sponges can be cultured in successive generations as well as clonal cultures, and sexual proliferation is possible. Even axenic culture techniques are developed (Rozenfeld and Curtis, 1980). A number of chemical and physical possibilities to direct or alter morphogenesis in freshwater sponges is already well documented (Rasmont, 1974, Benfey and Reiswig, 1982, Imsiecke et al., 1994). Hence sterile, synchronized, even clonal cultures are established and at hand. Moreover the morphology of the freshly developed, young sponge is reproducable. Thus abnormalities in morphogenesis are easily detectable. Adult tissue from these cultures can be dedifferentiated to stem cells and used for further studies. Therefore sponges are already discussed to be good models to investigate the evolution of basic features crucial for multicellularity and common to all metazoa (Coutinho et al., 2003, Müller, 2003, Müller et al., 2004a, Müller et al., 2004b). The one obstacle, which is still keeping

Fig. 1. Gross morphologies of young, functional sponges. (A) Undercover culture. Setup for two-dimensional growth after hatching. (B) Typical morphology of a young sponge (top view) grown in the setup shown in (A). The arrow indicates the remaining gemmule. The young sponge grew under a cover glass. The arrowhead indicates the singular oscular tube. (C) Young sponge after hatching but before the erection of the oscular tube. In this state particle bombardment was performed. (D) Young sponge after erection of the oscular tube indicated by the arrow (top view). (E) Schematic drawing of the reproducible morphology of a young sponge (median cut) after (Weissenfels, 1989). eK, incoming canal; GK, choanocyte chamber; aK, outgoing canal; At, atrium; $M$, mesohyl; SR, subpinacodermal cavity; Po, ostium; $P D$, pinacoderm; $P C$, pinacodermal cell; $N$, spicula; OR, oscular tube; Bl, basopinacodermal layer; arrows indicate the water current. Bars, $1 \mathrm{~mm}$. researchers from experimentally accessing sponges as a system for early metazoan gene function, has been the inability to apply functional genomics with the heterologous gene expression in sponges. If achieved, transgenic sponges will elucidate the function of ancestral genes in the control of morphogenesis, differentiation, immune self recognition and controlled cell death. Morphogenes will be either suppressed or over expressed to result in morphogenetic changes. Similarly appealing systems for the cnidarian Hydra are already established and we now would like to go a step further towards the origin of metazoa (Galliot and Schmidt, 2002; Wittlieb et al., 2006; Khalturin et al., 2007; Siebert et al., 2008). Hence we searched for promoters and marker proteins that function in sponges and are detectable after expression. As a promoter we chose the immediate early promoter of the cytomegalovirus (CMV), which is used for high expression levels, especially in mammalian cell cultures. As a marker protein we chose the red fluorescence protein DsRed2, derived from a red fluorescent protein of the coral Discosomasp. Its excitation and emission maxima are way further red than the ones from green fluorescence protein (GFP) derivatives, suggesting DsRed2 as a second marker in co detection experiments with GFP. DsRed2 is also very convenient, because in general the level of background autofluorescence detectable is significantly lower at longer wavelengths. DsRed2 under the control of the CMV promoter is commercially available with the vector pDsRedN1. We here report the first heterologous expression of the marker protein DsRed2 under the control of the CMV promoter in young specimens of the freshwater sponge species Spongilla lacustris Linnaeus 1758.

\section{Results and Discussion}

Fifteen gemmulae were each placed between two adjacent cover slips on glass object carriers and allowed to hatch (Fig. 1A). After hatching the gross morphology of the young sponges was observed and found to be uniform throughout the complete

A
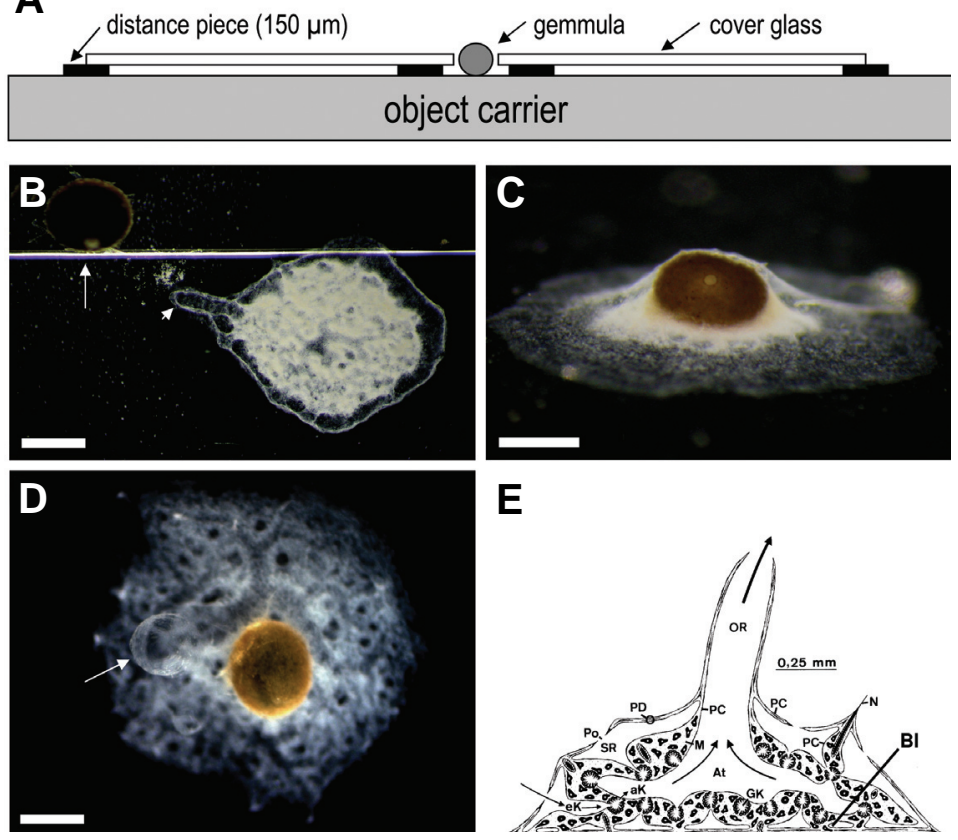

E

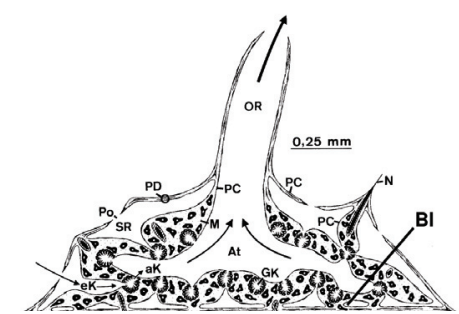


sample. All specimens grew two-dimensionally between the cover slip and the object carrier, showed a rounded outline and one oscular tube (Fig. 1B). This reproducibility of the young sponges' gross morphology would clearly make it easy to observe aberrations in the formation of e.g. the first body axis which runs along the oscular tube and is apparently not necessarily depending on gravity.

For the transfection experiments, gemmulae were allowed to hatch on cover glasses. Directly after hatching and before the erection of the oscular tube (Fig. 1C), the specimens underwent particle bombardment to transfect the specimen with the PDsRed2-N1 vector. All fifteen specimens showed the same gross morphology afterwards: the remains of the gemmula were used for scaffolding, the outline was round and one oscular tube was erected perpendicularly to the cover glass (Fig. 1 D,E). Obviously neither the transfection, nor the particle bombardment resulted in aberrant gross morphologies.

We observed living, functional, young sponge specimens, $48 \mathrm{~h}$ after transfection. They showed the gross morphology depicted in Fig. 1D and already started to pump water through their canal system (Pfannkuchen et al., 2009). To check for background or autofluorescence, hence the specificity of the applied filter set, we observed untreated specimens and specimens treated with unloaded particles (Fig. 2 G-I). Five untreated specimens showed no cellular fluorescence. Five specimens which were treated with unloaded particle bombardment showed no cellular fluorescence as well. In all five specimens treated with loaded particle bombardment we could find bright cellular fluorescence within the basal cell layer of fully developed young sponges (Fig. 2). We did not enumerate the total number of transfected cells or the transfection rate, because we only observed the basopinacodermal layer. But approximately twenty transfected cells could be found in $1 \mathrm{~mm}^{2}$ of basopinacoderm. In most cases two or three fluorescent cells could be detected close to each other like shown in Fig. $2 \mathrm{C}-\mathrm{F}$. The fluorescent signal was localized in the cytoplasm but showed a somewhat uneven distribution indicating accumulation of the fluorescent molecules. The outlines of the overlapping cells, the cytoplasmatic fluorescence as well as their nuclei are recognisable in the same focal layer (Fig. 2). The nuclei showed no fluorescence.

Thus, we conclude that after transfection of hatching tissue of Spongilla lacustris with the vector PDsRed2-N1 via particle bombardment, the young sponges developed normally and contained transfected cells. These cells expressed high levels of DsRed2 under the control of the CMV promoter. Due to the observation of groups of fluorescent cells, one can hypothesize that the fluorescence is inherited by the daughter cells after cell division. We so far cannot prove this, but rather assume a transient transfection, which would be diluted in daughter cells.

Apparently the fluorescent molecule folded correctly and presumably also polymerized (Baird et al., 2000, Garcia-Parajo etal.,
2001, Sacchetti et al., 2002). This shows that PDsRed2-N1 is a suitable vector to transport DNA into sponge cells, and express the transferred sequence. The CMV promoter yielded sufficiently high expression of the marker protein to be detected with fluorescence microscopy. In the described experiments, the young sponges grew on cover slips, which allowed visual inspection of the living specimens' basopinacodermal layer from underneath. Presumably those cells building the attachment site and later the basal layer of the sponge after hatching, have the highest probability to be hit by gold particles, especially as the particles are stopped by the cover glass. Our detection method, using inverse microscopy, allowed very good observations of the basopinacodermal layer. But with this method we did not look for transfected cells further than $300 \mu \mathrm{m}$ away from the basopinacoderm. Hence, transfected cells which moved away from the basal layer into the sponge body were not observed.

Future experiments will have the DsRed2 sequence replaced by, or coexpressed with, genes of interest (i.e. morphogenes). Now that we proved heterologous expression in functional sponges to be possible, we consider this organism as ready for functional genetics. In addition to looking for sequence similarities, this will allow the investigation of functional homologies of morphogenes and others in the most basal extant metazoa. Five years ago possible constructs for heterologous expression in Hydra vulgaris were reported'(Boettger et al., 2002, Miljkovic et al., 2002). We 
herewith finally reached the base of the metazoan phylogeny with a functional expression system in freshwater sponges.

\section{Materials and Methods}

Sponge material and gemmulae were collected in Lake Constance, Germany by SCUBA diving following the CMAS rules for scientific diving. The gemmulae were directly cooled at $4^{\circ} \mathrm{C}$ and kept at $4^{\circ} \mathrm{C}$ for three months.

For hatching single gemmulae were transferred to cover glasses or sandwich constructs in sterile filtered freshwater resembling Rasmonts M-Medium (Rasmont, 1961). After four days at room temperature the gemmulae started to hatch.

For the examination of two-dimensional growth between cover glass and object carrier single gemmulae were positioned inbetween two adjacent cover glasses on an object carrier (Fig. 1A) and were also transferred to M-Medium at room temperature for hatching.

For the particle bombardment single gemmulae were put on cover glasses in M-Medium at room temperature for hatching. One day after hatching, particle bombardment was performed in a Bio-Rad Biolistic Particle Delivery System (PDS-1000/He) (Bio-Rad, Hercules, USA). The distance for the bombardment was $2.5 \mathrm{~cm}$. We used 450 psi rupture disks from Bio-Rad and according macro carriers from Bio-Rad. One $\mu \mathrm{m}$ gold carriers were covered with PDsRed2-N1 vector DNA (Clontech Laboratories inc., Mountain View, USA) in a $0.16 \mathrm{mg} / \mathrm{ml}$ plasmid solution in water. Subsequently $17 \mathrm{mM}$ Spermidin (Carl Roth GmbH + Co. KG, Karlsruhe, Germany) and $1.7 \mathrm{M} \mathrm{CaCl}_{2}$ (Carl Roth $\mathrm{GmbH}+$ Co. KG, Karlsruhe, Germany) was added. After washing the gold particles twice in $98 \%$ Ethanol (Carl Roth $\mathrm{GmbH}+\mathrm{Co}$. KG, Karlsruhe, Germany) they were transferred to the macrocarriers. We applied $0.3 \mathrm{mg}$ gold particles for each bombardment.

Microscopic examination was performed on a Zeiss Axiovert $200 \mathrm{M}$ microscope (Zeiss, Oberkochen, Germany) on living specimens mounted as described on cover glasses. The fluorescent signal of mature DsRed2 molecules (Excitation | Emission Maxima: $558 \mathrm{~nm} \mathrm{|} 583 \mathrm{~nm}$ ) was detected applying the filterset (BP 550/25 nm | FT $570 \mathrm{~nm}$ | BP 605/70 nm) using an Axiocam MR (Zeiss, Oberkochen, Germany). Exposure time was 58 $\mathrm{ms}$. The same exposure time with the same gamma correction values resulted in no signal whatsoever in the untreated specimens as well as in the control specimens after bombardment with unloaded (no vector) particles. Control specimens were tested together with the transfected specimens at $48 \mathrm{~h}$ after transfection.

\section{Acknowledgements}

We are thankful to Reiner Eckert, for help with the PDsRed2-N1 Vector and to Björn Krenz for help with the particle bombardment. This work was supported by the research project BIOTECmarin (O3F0414D), funded by the FederalMinistry of Education and Research(BMBF) and the Universität Stuttgart, Germany.

\section{References}

ADELL, T., GREBENJUK, V.A., WIENS, M. and MÜLLER, W.E.G. (2003a). Isolation and characterization of two $T$-box genes from sponges, the phylogenetically oldest metazoan taxon. Dev Genes Evo/213: 421-434.

ADELL, T. and MÜLLER, W.E.G. (2004). Isolation and characterization of five Fox (Forkhead) genes from the sponge Suberites domuncula. Gene 334: 35-46.

ADELL, T., NEFKENS, I. and MÜLLER, W.E.G. (2003b). Polarity factor 'Frizzled' in the demosponge Suberites domuncula: identification, expression and localization of the receptor in the epithelium/pinacoderm(1). FEBS Lett 554: 363368.

BAIRD, G.S., ZACHARIAS, D.A. and TSIEN, R.Y. (2000). Biochemistry, mutagenesis, and oligomerization of DsRed, a red fluorescent protein from coral. Proc Natl Acad Sci USA 97: 11984-11989.
BENFEY, T.J. and REISWIG, H.M. (1982). Temperature, pH and photoperiod effects upon gemmule hatching in the freshwater sponge, Ephydatia muelleri (Porifera, Spongillidae). J EXp Zoo/221: 13-22.

Boettger, A., ALEXANDROVA, O., CIKALA, M., SCHADE, M., HEROLD, M. and DAVID, C.N. (2002). GFP expression in Hydra: Lessons from the particle gun. Dev Genes Evol 212: 302-305.

COUTINHO, C.C., FONSECA, R.N., MANSURE, J.J. and BOROJEVIC, R. (2003). Early steps in the evolution of multicellularity: deep structural and functional homologies among homeobox genes in sponges and higher metazoans. Mech Dev 120: 429-440.

ERPENBECK, D. and WÖRHEIDE, G. (2007). On the molecular phylogeny of sponges (Porifera). Zootaxa 107-126.

GARCIA-PARAJO, M.F., KOOPMAN, M., VAN DIJK, E.M.H.P., SUBRAMANIAM, V. and VAN HULST, N.F. (2001). The nature of fluorescence emission in the red fluorescent protein DsRed, revealed by single-molecule detection. Proc Nat/ Acad Sci USA 98: 14392-14397.

GALLIOT, B. and SCHMID, V. (2002). Cnidarians as a model system for understanding evolution and regeneration. Int. J. Dev. Biol. 46: 39-48.

HOSHIYAMA, D., SUGA, H., IWABE, N., KOYANAGI, M., NIKOH, N., KUMA, K. I., MATSUDA, F., HONJO, T. and MIYATA, T. (1998). Sponge Pax cDNA related to Pax-2/5/8 and ancient gene duplications in the Pax family. JMo/ Evo/47: 640648.

IMSIECKE, G., BOROJEVIC, R., CUSTODIO, M. and MÜLLER, W.E.G. (1994). Retinoic acid acts as a morphogen in freshwater sponges. Invertebr Reprod Dev 26: 89-98.

KHALTURIN, K., ANTON-ERXLEBEN, F., MILDE, S., PLOETZ, C., WITTLIEB, J., HEMMRICH, G. and BOSCH, T.C.G. (2007). Transgenic stem cells in Hydra reveal an early evolutionary origin for key elements controlling self-renewal and differentiation. Dev Bio/309: 32-44.

MARTINDALE, M.Q. (2005). The evolution of metazoan axial properties. Nat Rev Genet 6: 917-927.

MILJKOVIC, M., MAZET, F. and GALLIOT, B. (2002). Cnidarian and bilaterian promoters can direct GFP expression in transfected Hydra. Dev Bio/246: 377390.

MÜLLER, W.E.G. (2003). The origin of metazoan complexity: Porifera as integrated animals. Integr Comp Bio/43: 3-10.

MÜLLER, W.E.G., KORZHEV, M., LE PENNEC, G., MÜLLER, I.M. and SCHRÖDER, H.C. (2003). Origin of metazoan stem cell system in sponges: First approach to establish the model (Suberites domuncula). Biomol Eng 20: 369-379.

MÜLLER, W.E.G., SCHWERTNER, H. and MÜLLER, I.M. (2004a). Porifera a reference phylum for evolution and bioprospecting: the power of marine genomics. Keio J Med53: 159-165.

MÜLLER, W.E.G., WIENS, M., ADELL, T., GAMULIN, V., SCHRÖDER, H.C. and MÜLLER, I.M. (2004b). Bauplan of Urmetazoa: Basis for genetic complexity of Metazoa. In Int Rev Cytol, vol. 235. Elsevier Inc., pp.53-91.

MÜLLER, W.E.G., WIENS, M., MÜLLER, I.M. and SCHRÖDER, H.C. (2004c). The chemokine networks in sponges: Potential roles in morphogenesis, immunity and stem cell formation. In Invertebrate cytokines and the phylogeny of immunity, (ed. BESCHIN, A. and MÜLLER, W. E. G.). Springer-Verlag, New York, Berlin, pp.103-143.

NICKEL, M., LEININGER, S., PROLL, G. and BRÜMMER, F. (2001). Comparative studies on two potential methods for the biotechnological production of sponge biomass. J Biotechno/92: 169-178.

OSTROM, K.M. and SIMPSON, T.L. (1978). Calcium and the release from dormancy of freshwater sponge gemmules. Dev Bio/64: 332-338.

PEROVIC, S., SCHRÖDER, H.C., SUDEK, S., GREBENJUK, V.A., BATEL, R., STIFANIC, M., MÜLLER, I.M. and MÜLLER, W.E. (2003). Expression of one sponge Iroquois homeobox gene in primmorphs from Suberites domuncula during canal formation. Evol Dev 5: 240-250.

PEROVIC-OTTSTADT, S., CETKOVIC, H., GAMULIN, V., SCHRODER, H.C., KROPF, K., MOSS, C., KORZHEV, M., DIEHL-SEIFERT, B., MULLER, I.M. and WERNER MULLER, E.G. (2004) Molecular markers for germ cell differentiation in the demosponge Suberites domuncula. Int. J. Dev. Biol. 48: 293-305.

PFANNKUCHEN, M., FRITZ, G.B., SCHLESINGER, S., BAYER, K. and BRÜMMER, F. (2009). In situ Pumping activity of the sponge Aplysina aerophoba, Nardo 1886. J Exp Mar Biol Eco/369: 65-71. 
RASMONT, R. (1961). Une Technique de culture des éponges d'eau douce en milieu controlé. Ann. Soc. Roy. Zool. Belg. 91: 147-155.

RASMONT, R. (1974). Stimulation of cell aggregation by theophylline in the asexual reproduction of fresh-water sponges (Ephydatia fluviatilis). Experientia 30: 792 794.

REISWIG, H.M. and MILLER, T.L. (1998). Freshwater sponge gemmules survive months of anoxia. Invertebr Bio/117: 1-8.

ROZENFELD, F. and CURTIS, A.S.G. (1980). A technique for sterile culture of fresh water sponges. Experientia 36: 371-373

SACCHETTI, A., SUBRAMANIAM, V., JOVIN, T.M. and ALBERTI, S. (2002). Oligomerization of DsRed is required for the generation of a functional red fluorescent chromophore. FEBS Lett 525: 13-19.

SIEBERT, S., ANTON-ERXLEBEN, F. and BOSCH, T.C.G. (2008). Cell type complexity in the basal metazoan Hydra is maintained by both stem cell based mechanisms and transdifferentiation. Dev Bio/313: 13-24.

STEELE, R.E. (2005). Genomics of basal metazoans. Integr Compa Bio/45: 639648.

WEISSENFELS, N. (1989). Biologie und Mikroskopische Anatomie der
Süßwasserschwämme (Spongillidae). Urban \& Fischer, München.

WIENS, M., MANGONI, A., D'ESPOSITO, M., FATTORUSSO, E., KORCHAGINA N., SCHROEDER, H.C., GREBENJUK, V.A., KRASKO, A., BATEL, R., MÜLLER, I.M. et al. (2003). The molecular basis for the evolution of the metazoan bodyplan: Extracellular matrix-mediated morphogenesis in marine demosponges. JMol Evol57: S60-S75.

WIENS, M. and MÜLLER, W.E.G. (2006). Cell death in Porifera: molecular players in the game of apoptotic cell death in living fossils. Can J Zoo/84: 307-321.

WILSON, H.V. (1907). On some phenomena of coalescence and regeneration in sponges. J Exp Zool 5: 245-252.

WITTLIEB, J., KHALTURIN, K., LOHMANN, J.U., ANTON-ERXLEBEN, F. and BOSCH, T.C.G. (2006). Transgenic Hydra allow in vivo tracking of individual stem cells during morphogenesis. Proc Nat/ Acad Sci USA 103: 6208-6211.

XIAO, S., HU, J., YUAN, X., PARSLEY, R.L. and CAO, R. (2005). Articulated sponges from the lower Cambrian Hetang Formation in southern Anhui, South China: their age and implications for the early evolution of sponges. Palaeogeogr Palaeoclimat. Palaeoecol. 220: 89-117.

\section{Further Related Reading, published previously in the Int. J. Dev. Biol.}

See our recent Special Issue Fertilization, in honor of David L. Garbers and edited by Paul M. Wassarman and Victor D. Vacquier at: http://www.ijdb.ehu.es/web/contents.php?vol=52\&issue=5-6

Human conjunctival epithelial precursor cells and their progeny in 3D organotypic culture Alfredo Rosellini, Sandra Papini, Claudio Giannarini, Marco Nardi and Roberto P. Revoltella Int. J. Dev. Biol. (2007) 51: 739-743

Wnt signaling in hydroid development: ectopic heads and giant buds induced by GSK-3beta inhibitors Werner Müller, Uri Frank, Regina Teo, Ofer Mokady, Christina Guette and Günter Plickert Int. J. Dev. Biol. (2007) 51: 211-220

The fate of larval flagellated cells during metamorphosis of the sponge Halisarca dujardini

Yulia I. Mukhina, Vadim V. Kumeiko, Olga I. Podgornaya and Sofia M. Efremova Int. J. Dev. Biol. (2006) 50: 533-541

Molecular markers for germ cell differentiation in the demosponge Suberites domuncula

Sanja Perovic-Ottstadt, Helena Cetkovic, Vera Gamulin, Heinz C. Schroder, Klaus Kropf, Claire Moss, Michael Korzhev, Barbel Diehl-Seifert, Isabel M. Muller and Werner E.G. Muller

Int. J. Dev. Biol. (2004) 48: 293-305

Cnidarians as a model system for understanding evolution and regeneration. Brigitte Galliot and Volker Schmid Int. J. Dev. Biol. (2002) 46: 39-48

Patterning a multi-headed mutant in Hydractinia: enhancement of head formation and its phenotypic normalization

Werner A Müller, Regina Teo and Frank Möhrlen

Int. J. Dev. Biol. (2004) 48: 9-15

Autoaggressive, multi-headed and other mutant phenotypes in Hydractinia echinata (Cnidaria: Hydrozoa)

Werner A Müller

Int. J. Dev. Biol. (2002) 46: 1023-1033

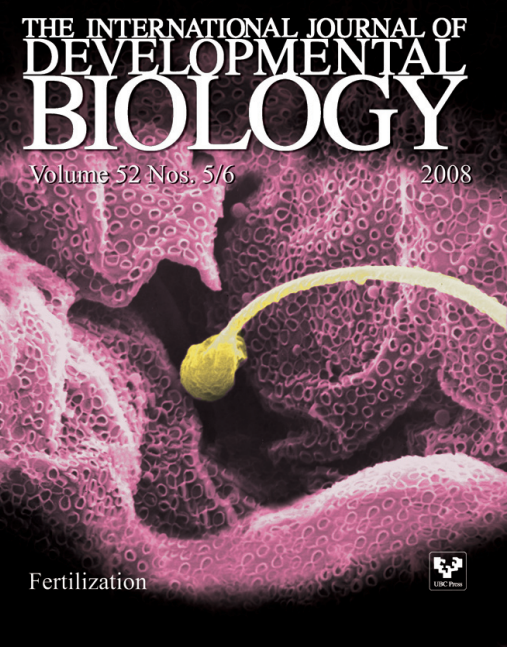

